\title{
Study of Lipid Profile in Cases of Intrauterine Growth Retardation
}

\author{
Shadab Khalid ${ }^{1}$, Khalid Beg², Ranjit Ambad ${ }^{3 *}$ \\ 1Demonstrator, ${ }^{3}$ Assistant Professor, Department of Biochemistry, \\ ${ }^{2}$ Senior Resident, Department of Anesthesiology, \\ Chandulal Chandrakar Memorial Medical College, Kurud Road, Durg District, Kachandur, Chhattisgarh, India.
}

\begin{abstract}
Purpose: To analyze the level of serum Total Cholesterol (Chol), High Density Lipoprotein (HDL), and Triglyceride (TG) in intrauterine growth retardation (IUGR).
\end{abstract}

Methods: For the study comprising total 40 cases for gestational age or Intrauterine Growth restriction babies born in the Department of Obstetrics and Gynecology, CCMMC Durg were selected. A total of 20 age and sex matched healthy subjects taken as control. The circulating levels of Chol, HDL and TG activity were assayed in the serum of control group and in study group.

Results: The correlation between serum triglyceride \& HDLCholesterol concentrations of IUGR group was found to be highly significant with $p$ value $<0.001$. This increased triglyceride level \& decreased HDL-Cholesterol level in small for date babies signifies onset of coronary heart diseases in later life. The differences in the serum triglyceride concentration were found to be strikingly different in the two groups of newborns. Serum triglyceride in the IUGR group was found to be $101.14 \pm 24.69 \mathrm{mg} / \mathrm{dl}$ that was significantly higher than that found in AFD control group with an average concentration of $74.33 \pm 13.15 \mathrm{mg} / \mathrm{dl}$ with a p value $<0.05$.

Conclusion: The findings that normal variations in fetal size and thinness at birth have implications for health throughout life have prompted a reevaluation of the regulation of fetal development. Impetus has been added to this reevaluation by recent findings showing that a woman's diet and body composition in pregnancy are related to cardiovascular disease risk factors and the prevalence of coronary heart disease in her offspring in adult life. These observations challenge the view that the fetus is little affected by changes in maternal nutrition

\section{INTRODUCTION}

Growth appears to be the best indicator of long-term fetal wellbeing and might be associated with development of abnormal states later in life. Distinct from their appropriately grown counterparts, growth restricted fetuses have physiological characteristics that are believed to alter permanently the development and metabolic functions of organs. In addition to increased morbidity and mortality, growth restriction has been associated with hypoglycemia, hypocalcemia, polycythemia and thrombocytopenia. Hypoinsulinemia decreased thyrotropin levels and diminished insulin growth factor I have been described in small for gestational age (SGA) infants. except in circumstances of famine. If, as we believe, a woman's own fetal growth and diet and body composition before and during pregnancy play a major role in programming the future health of the children, mothers will want to know what they can do to optimize the intrauterine environment they provide for their babies. The complexities of fetal growth and development are, however, such that currently available data form no basis for changing dietary recommendations for pregnant women. The long time-scale over which the effects of an adverse intrauterine environment act dictate that we now need to progress beyond epidemiologic associations to greater understanding of the cellular and molecular processes that underlie them.

Keywords: Intrauterine Growth Retardation, AFD, HDL, PI, TG, CHOL, FTPT.

\section{${ }^{*}$ Correspondence to:}

Ranjit Sidram Ambad,

Assistant Professor, Dept. of Biochemistry, Chandulal Chandrakar Memorial Medical College, Kachandur, Chhattisgarh, India.

Article History:

Received: 19-08-2016, Revised: 27-08-2016, Accepted: 10-09-2016

\begin{tabular}{|l|r|}
\hline \multicolumn{2}{|c|}{ Access this article online } \\
\hline Website: & Quick Response code \\
www.ijmrp.com & \\
\hline DOI: & \\
10.21276/ijmrp.2016.2.5.019 & \\
\hline
\end{tabular}

Physiological differences have been noted in growth restricted infants. Intrauterine amino acid disturbances similar to biochemical changes seen in postnatal protein deprived states have been detected. Protein metabolism defect and altered lipid metabolism also have been described. Recent research suggests that several of major disease of later life, including coronary heart disease, hypertension \& type II diabetes originate in impaired intrauterine growth and development. These diseases may be consequence of programming whereby a stimulus or insult at a critical, sensitive period of early life has a permanent effect on structure, physiology and metabolism. Evidence that coronary 
heart disease, hypertension, and diabetes are programmed came after longitudinal studies of 25000 UK men \& women in which size at birth was related to occurrence of disease in middle age. People who were small or disproportionate at birth had high rates of coronary heart disease, high blood pressure, high cholesterol concentration and abnormal glucose insulin metabolism.

The "Fetal Origins" hypothesis proposes that alternations in fetal nutrition and endocrine status result in development adaptations that permanently change structure, physiology, and metabolism, thereby predisposing individuals to cardiovascular, metabolic, and endocrine disease in adult life. The process whereby a stimulus or insult at a sensitive or critical period of development has long-term effects is termed programming. In evolutionary terms, the phenomenon is likely to reflect the benefits of plasticity during early development. Consistent with this, it is thought that coronary heart disease may be a consequence of fetal adaptations to under nutrition that are beneficial for short-term survival even though they are harmful to health in post reproductive life.

There is just enough reaching the amount specified or needed data on serum lipid levels in IUGR newborn and various studies both in India and abroad have failed to keep separate from the rest low birth weight babies into three diverse categories- full term small for gestational age (SGA), preterm appropriate for gestational age (AGA), \& preterm small for gestational age (SGA). Indian studies on lipid levels in SFD babies are rarely found. This study is therefore aimed at analyzing the lipid levels in IUGR and healthy newborns and at evaluation of the differences between them.

The term IUGR refers to an infant whose intrauterine growth is less than expected for gestational age at birth. IUGR represents deviation and reduction in the expected fetal growth pattern and is associated with higher perinatal mortality and morbidity rates.

Growth restricted fetus may show symmetric or asymmetric growth at birth. Infants with symmetric IUGR have reduced weight, length and head circumference at birth. For infants with asymmetric IUGR, higher rates of intrauterine infections, chromosomal abnormalities, dysmorphic syndromes and intrauterine toxins (alcohol) were described as reasons for the growth restriction.

Weight of infants with asymmetric growth retardation is affected, with a relatively normal or head sparing growth pattern. Asymmetric IUGR is associated with maternal medical conditions such As preeclampsia, chronic hypertension and uterine anomalies.

Data suggest that the more severe the growth restriction, the worse are the neonatal outcomes, including risk of stillbirth, fetal distress, neonatal hypoglycemia, hypocalcaemia, low Apgar scores and mortality.

Undernourishment in utero appears to be associated with persisting changes in the metabolic functions. Birth weight influences the lipoprotein profile and cholesteryl ester transfer protein (CETP), which promotes a proatherogenic lipoprotein profile in plasma by determining chemical, physical and biological properties of the respective lipoprotein particle in neonates.

High TG and low HDL levels which may be found in SGA neonates might result from increase cholestryl ester transfer and may in part explain the increased risk of Coronary Heart Disease of SGA neonates in later life. Newborn babies with IUGR have significant maximum aortic thickening with hypertriglyceridemia suggesting that prenatal events might predispose to later cardiovascular risk.

\section{INTRAUTERINE GROWTH RETARDATION \\ Definition}

The infant with low birth weight (less than $2500 \mathrm{~g}$ ) is not always premature (earlier than 37 weeks). Worldwide more than 20 million infants are born weighing less than $2500 \mathrm{~g}$. between $30 \%$ and $40 \%$ of these infants are born at term gestation and are therefore under grown (Small for Gestational Age) ${ }^{1}$.

\section{Ponderal Index}

The terms intrauterine growth retardation (IUGR) and Small for Gestational Age (SGA) were used inter changeably in the past. Although related they are not synonymous. IUGR is the failure of normal fetal growth caused by multiple adverse effects on fetus, while SGA describes an infant whose weight is lower than population norms ${ }^{2}$. Ponderal index can be used to identify infants whose soft tissue mass is below normal for the stage of skeletal development. The Ponderal index (PI) is arrived at by the following formula:

$\mathrm{PI}=$ birth weight (gms) $\div$ (Crown heal length) $31 \times 100$

A ponderal index below the $10^{\text {th }}$ percentile may be used to identify IUGR infants correctly. This can affect the long-term outcome. Thus all IUGR infants may not be SGA and all SGA infants may not be small due to growth restrictive process. A low neonatal ponderal index is defined as less than 1 SD below a mean 2.0 and SGA is considered as birth weight below the $10^{\text {th }}$ percentile ${ }^{3}$.

Foetal ponderal index can also be calculated by ultrasound examination and compared with the neonatal PI. Foetal PI had been found to be predictor of IUGR with the sensitivity and specificity of $76.9 \%$ and $82 \%$. Data suggests that foetal PI could be used to rule out IUGR with reasonable accuracy with a negative predictive value of $96.4 \%$. Various studies have shown a good sensitivity of the application of intrauterine $\mathrm{PI}$ in the diagnosis of asymmetrical IUGR. Wider use of intrauterine PI and the IUGR can be used for the evaluation of fetal retardation because of the high predictable value of the negative test. In utero $\mathrm{PI}$ proved to be a valuable index in the prediction of foetal outcome, in those cases of IUGR in whom the in utero PI was smaller than one SD4.

However, studies have shown that fetal PI is a poor predictor of discordant growth and should be employed cautiously in twin and triplet gestations. PI is not a superior predictor than either birth weight or body mass index for selected short term outcomes in newborns.

For chronic diseases intrauterine environment seems to be important, it is therefore useful to identify the babies with low ponderal index, as it is a reliable predictor of long-term complications including microabluminuria, insulin resistance, high blood pressure and cardiovascular diseases ${ }^{5}$.

PI has been used to assess the asymmetrical IUGR because low birth weight and IUGR tends to reoccur in brother or sister and clustering of $\mathrm{PI}$ in sibling even persists after controlling for factors such as race, gender, maternal age, gravidity, year of birth, gestational age, pregnancy complications and poor maternal illnesses. A hospital-based study reported in this issue revealed that $40 \%$ of low birth weight babies had asymmetrical body proportion, which can have implication for future long-term comorbidities $^{6,7}$. 
A study under taken at Nepean Hospital showed that PI appears to be better measure of infants with IUGR problems than birth weight percentiles. Use of curve for gestational age together with other growth curves improves the nutritional assessment of newborns. Further studies should be designed to develop strategies for the short, medium and long-term management of identified risk groups ${ }^{8}$.

Lin and colleagues $(1991)^{9}$ suggest that the timing of the risk factors is more important than the risk factor itself in determining whether symmetric or asymmetric growth restriction is seen. They reported that asymmetric growth restriction is more commonly seen from effects on the fetus later in gestation. In their study, symmetric IUGR resulted in higher levels of prematurity \& higher rates of neonatal morbidity. In contrast Villar and associates $(1990)^{10}$ have shown that infants with low ponderal index measurement had higher risk for low apgar scores, long hospitalization, hypoglycemia and asphyxia at birth than infants with symmetric IUGR. There is evidence to suggest that infants with asymmetric IUGR show better gains in weight \& Length in the postnatal period than symmetrically restricted infants (May et al 2001). Other investigators propose that IUGR represents a continuum with asymmetric IUGR occurring as the severity of the growth retardation increases. Data also suggests that the more severe the growth restriction the worse the neonatal outcomes including the risk of still birth, fetal distress, neonatal hypoglycemia, hypocalcemia, polycythemia, low Apgar scores \& mortality ${ }^{11,12}$.

\begin{tabular}{ll}
\hline & Causes of IUGR \\
\hline${ }^{*}$ Genetic & $\begin{array}{l}\text { Inheritance, chromosomal } \\
\text { abnormalities, fetal gender }\end{array}$ \\
& Low maternal pre pregnancy weight, \\
*Maternal & low pregnancy weight gain, ethnicity, \\
Constitutional & socioeconomic status, history of IUGR. \\
Effects & Low pre pregnancy weight (BMI), low \\
*Nutrition & pregnancy weight gain, malnutrition, \\
& maternal anemia. \\
& TORCH, Malaria etc. \\
${ }^{*}$ Infectioins & High altitude, maternal congenital heart \\
*Decreased O $_{2}$ & disease, hemoglobinopathies, chronic \\
Carrying Capacity & anemia, asthma. \\
& Abnoraml uterine anatomy, uterine \\
*Uterine/Placental & fibroid, vascular abnormalities, \\
Anatomy & placentaq previa, placental abruption. \\
& Maternal vasculitis, decreased \\
*Uterine/Placental & uteroplacental perfusion, maternal \\
Function & illness (preeclampsia, chronic \\
& hypertension, diabetes, rental disease). \\
& Tobacco, ethanol, lead arsenic \\
\hline
\end{tabular}

A fetus with IUGR may be born small for age (SGA) or appropriate for gestational age (AGA) according to population reference charts. There is no universal agreement in the definition of SGA or LGA infants. Various definitions appear in the medical literature, making comparison between studies difficult. Additionally investigators have shown that the prevalence of fetal growth restriction varies according to the fetal growth curves used (Alexander et al 1996) ${ }^{13}$. Historically SGA infants were defined as those with measurements bellow the tenth percentile. Some investigators however also use measurement below the third percentile or two standard deviation below the mean derived from population charts to define SGA. Other researcher reported a threshold of increased adverse outcomes in infants born with measurement below third percentile \& suggest that this level of restriction represents a clinically relevant measurement. Other researchers have found higher rates of neonatal complications when the $15^{\text {th }}$ percentile of birth weights is used as cutoff level ${ }^{14}$.

\section{Determinants of preterm birth and intrauterine growth} Restriction in developing country settings ${ }^{15}$

\begin{tabular}{ll}
\hline Preterm & IUGR \\
\hline Genital tract infection & Low energy intake \\
Multiple birth & Low gestational weight gain \\
$\begin{array}{l}\text { Pregnancy induced } \\
\text { hypertension }\end{array}$ & Low pre pregnancy BMI \\
Low pre pregnancy BMI & Short stature \\
Incompetent cervix & Malaria \\
Prior preterm birth & Smoking \\
Abruption placentae & Primipara \\
Heavy work & PIH \\
Cigarette smoking & Congenital anomalies Other \\
& genetic factor \\
\hline
\end{tabular}

\section{MATERIAL AND METHODS}

The present work was conducted in the Department of Pediatrics, Dept. of Obstetrics and Gynecology and Dept. of medical Biochemistry, Chandulal Chandrakar Memorial Medical College Kachandur. It included 60 newborns of these twenty were full term appropriate for gestational age control babies and forty were full term small for gestational age babies that were healthy and selected on the basis of Ponderal index $<2$.

\section{Selection Criteria \\ Controls}

A control newborn was of 37-42 week gestational age as assessed by New Ballards Scoring System at birth. The weight was recorded at birth using a spring type of machine with an accuracy of $+/-50$ grams. The selected control newborns weight between 2.5 to $3.2 \mathrm{~kg}$ at birth.

\section{Cases}

The cases selected were full term small for gestational age or Intrauterine Growth restriction babies born in the Department of Obstetrics and Gynecology, CCMM Kachandur. The cases selected on the basis of Ponderal index which was calculated as:

Ponderal Index $=\left[(w t\right.$ in grams $\left.) \div(\text { length in } \mathrm{cms})^{3}\right] \times 100$ The newborn babies with ponderal index less than 2 were selected as cases. The weight of babies was recorded at birth using spring type of weighting machine with an accuracy of $+/-50$ grams. All babies selected as cases delivered by uncomplicated deliveries either normal vaginal delivery or caesarean section.

\section{Sample Collection}

Taking all aseptic \& universal precautions $5 \mathrm{ml}$ of blood sample was collected from all cases \& control babies in a plain \& sterilized glass vial. Blood was allowed to clot and the serum was separated by centrifugation and estimation of total cholesterol, triglycerides, HDL-Cholesterol was carried out by using commercial available kits $^{16-18}$. 


\section{RESULTS}

The present study was done in the department of Medical Biochemistry, Chandulal Chandrakar Memorial Medical College Kachandur in association with Department of Pediatrics. The work comprised of 40 cases of IUGR \& 20 control healthy AFD newborns.

Analysis of demographic data suggests that there is statistically significant difference between the birth weights of the two groups. The study included 37 male and 23 female newborns, the study had equal ration of male \& female babies in both the groups.

It is evident from the above table that there are higher changes of IUGR baby of birth order.

It is evident from the above table that there is statistically significant difference between Ponderal index of the IUGR and AFD babies.

It is evident from the above table that cholesterol is significantly decreased in IUGR group as compared to AFD; serum triglyceride conc. was significantly increased and HDL-C cond. Decreased (statistically insignificant) in IUGR group as compared to controls. It is evident from the above table that the correlation between Triglyceride and HDL-Cholesterol levels is highly significant statistically.
Table 1: Comparison of cases and controls according to Demographic profile.

\begin{tabular}{lccc}
\hline Birth Weight & Cases & Controls & P-value \\
\cline { 2 - 4 } (in kgs) & $2.00 \pm 0.13$ & $2.88 \pm 0.24$ & $<0.001$ \\
\hline
\end{tabular}

Table 2: Sex distribution of cases and controls

\begin{tabular}{lccc}
\hline & Cases & Controls & Total \\
\hline Male & 26 & 11 & 37 \\
Female & 14 & 09 & 23 \\
Total & 40 & 20 & 60 \\
\hline
\end{tabular}

Table 3: Distribution of cases and controls according to birth order

\begin{tabular}{lcc}
\hline Birth Order & Cases & Controls \\
\hline $\mathbf{1}$ & 07 & 05 \\
$\mathbf{2}$ & 14 & 10 \\
$\mathbf{> 2}$ & 19 & 05 \\
\hline
\end{tabular}

Table 4: Comparison of cases and controls on the basis of anthropometric measurements

\begin{tabular}{lccc}
\hline & Cases & Controls & P-value \\
\hline Length & $48.6 \pm 3.2 \mathrm{~cm}$ & $50.2 \pm 2.9$ & NS \\
Head c & $33.8 \pm 1.7 \mathrm{~cm}$ & $34.6 \pm 105$ & NS \\
Ponderal Index & $1 . \quad 0.10$ & $2024 \pm 0.11$ & $<0.05$ \\
\hline
\end{tabular}

Table 5: Comparison of lipid profile of IUGR and AFD newborns

\begin{tabular}{llccc}
\hline & & Cases & Controls & P-value \\
\hline $\mathbf{1}$ & Total Cholesterol (mg/dl) & $85.27 \pm 29.1 \mathrm{~cm}$ & $104.03 \pm 10.16$ & $<0.05$ \\
$\mathbf{2}$ & Triglycerides (mg/dl) & $101.14 \pm 28.26$ & $74.33 \pm 13.15$ & $<0.05$ \\
$\mathbf{3}$ & HDL-Cholesterol (mg/dl) & $17.45 \pm 5.73$ & $40.74 \pm 6.46$ & $\mathrm{NS}$ \\
$\mathbf{4}$ & LDL-Cholesterol (mg/dl) & $47.77 \pm 28.26$ & $47.5914 .82 \pm 11.03$ & $\mathrm{NS}$ \\
$\mathbf{5}$ & VLDL-Cholesterol (mg/dl) & $20.22 \pm 4.93$ & $14.82 \pm 2.62$ & $<0.05$ \\
\hline
\end{tabular}

Table 6: Comparison of Triglyceride and HDL-Cholesterol of IUGR and AFD newborns

\begin{tabular}{lccc}
\hline & Cases & Controls & P-value \\
\hline Serum TG $(\mathrm{mg} / \mathrm{dl})$ & $101.14 \pm 24.69 \mathrm{~cm}$ & $74.33 \pm 13.15$ & $<0.05$ \\
Serum HDL-C $(\mathrm{mg} / \mathrm{dl})$ & $17.45 \pm 5.73$ & $40.74 \pm 6.46$ & $\mathrm{NS}$ \\
\hline
\end{tabular}

Table 7: Correlation between Triglyceride and HDL-Cholesterol of IUGR (Small for Date) Newborns

\begin{tabular}{ll}
\hline Serum TG $(\mathrm{mg} / \mathrm{dl})$ & $101.14 \pm 24.69$ \\
\hline Serum HDL-Cholesterol $(\mathrm{mg} / \mathrm{dl})$ & $17045 \pm 5.73$ \\
P-Value & $<0.001$ \\
\hline
\end{tabular}

\section{DISCUSSION}

This study included the 60 newborns babies out of which 40 were full term small for gestational age newborns and remaining twenty were full term appropriate for date healthy newborns. All the newborns were carefully selected $\&$ any acute complication was ruled out. These babies were assessed by their serum lipid concentrations, serum was collected carefully. The different results \& observations that were assessed in the study are discussed further.
The correlation between serum triglyceride \& HDL-Cholesterol concentrations of IUGR group was found to be highly significant with $p$ value $<0.001$. This increased triglyceride level \& decreased HDL-Cholesterol level in small for date babies signifies onset of coronary heart diseases in later life.

The differences in the serum triglyceride concentration were found to be strikingly different in the two groups of newborns. Serum triglyceride in the IUGR group was found to be $101.14 \pm 24.69$ 
$\mathrm{mg} / \mathrm{dl}$ that was significantly higher than that found in AFD control group with an average concentration of $74.33 \pm 13.15 \mathrm{mg} / \mathrm{dl}$ with a $p$ value $<0.05$. Different in the two groups was corresponding to various previous studies that showed similar results with higher triglyceride concentrations in small for date newborns. Increased triglyceride levels in small for date babies signifies intrauterine malnutrition and lipid breakdown \& this is an important biochemical parameter of intrauterine growth retardation.

The difference between the serum concentration of HDL and LDL cholesterol in the two groups was interestingly different than the difference of total cholesterol. The HDL cholesterol of AFD newborns was found to be $40.74 \pm 5.73(\mathrm{mg} / \mathrm{dl})$, that was $42 \%$ higher than that found in SFD newborns with an average of 17.45 $\pm 5.73(\mathrm{mg} / \mathrm{dl})$. But the LDL cholesterol concentration showed reverse relationship between the two groups with average LDL cholesterol concentration in SFD newborns being $47.77 \pm 28.26$ $\mathrm{mg} / \mathrm{dl}$ which was higher than found in AFD control newborns with $47.59 \pm 11.03 \mathrm{mg} / \mathrm{dl}$. This difference though was not found to be statistically significant but clearly states that there is a definite change in the lipid metabolism of the two groups that could lead to diseases in the later life while the total cholesterol was higher in the AFD newborns, but the distribution of LDL and HDL cholesterol showed that LDL cholesterol which is more atherogence in adults is found in higher concentrations in IUGR Newborns ${ }^{19}$.

Analysis of demographic factors shows that the birth weight of the two groups was significantly different with $p$ value $<0.001$. The average birth weight of the cases was $2.00 \pm 0.13 \mathrm{~kg}$ in comparison to control group with average birth weight of $2.88 \pm$ 0.24 .

There were 37 male and 23 female newborns in this study. The small for date \& appropriate for date group included $60 \%$ male and $40 \%$ female newborns between the two groups helped to remove any confounding factors arising due to sex of the child.

The analysis of the birth order of the babies suggest that with increasing birth order or increasing number of children in family leads to increased incidence of IUGR babies. It was concluded that there is higher chance of having SFD or IUGR baby of birth order more than 2. The study included SFD newborns born in this hospital. To find out that IUGR is more in preterm was beyond the study \& therefore was not analyzed.

The difference between the length \& head circumstance of the two group showed that both were increased in the appropriate for date babies with the average length \& head circumference of the control group being $50.2 \pm 2.9 \mathrm{~cm} \& 34.6 \pm 1.5 \mathrm{~cm}$ respectively as against $48.6 \pm 3.2 \mathrm{~cm}$ and $33.8 \pm 1.7 \mathrm{~cm}$ respectively in the IUGR neonates. But the difference was not statistically significant.

The most significant difference was found in the ponderal indices of the two groups. The ponderal index which was calculated as [wt. in gm-(crown to heal length in $\left.\mathrm{cm})^{3}\right]^{*} 100$ was used to differentiate between the two groups of newborns. The average PI of IUGR group was $1.91 \pm 0.10$ while that of AFD babies was calculated to be $2.24 \pm 0.11$; this difference was found to be statistically significant with $P$ value $<0.05$. This finding correlates well with other research associates, where PI has been used to identify IUGR and to differentiate between symmetrical \& asymmetrical IUGR ${ }^{20,21}$.

The estimation of the serum lipid concentrations showed that the mean total cholesterol level of $85.27 \pm 29.1 \mathrm{mg} / \mathrm{dl}$ in IUGR neonates was about $81 \%$ of the total cholesterol concentration of full term appropriate for date newborns with mean total cholesterol of $104.03 \pm 10.16 \mathrm{mg} / \mathrm{dl}$. This difference in total cholesterol of two groups was found to be significant with $p$ value $<0.05$. The total serum cholesterol level in full term healthy newborns was found to be higher.

\section{CONCLUSION}

The findings that normal variations in fetal size and thinness at birth have implications for health throughout life have prompted a reevaluation of the regulation of fetal development. Impetus has been added to this reevaluation by recent findings showing that a woman's diet and body composition in pregnancy are related to cardiovascular disease risk factors and the prevalence of coronary heart disease in her offspring in adult life. These observations challenge the view that the fetus is little affected by changes in maternal nutrition except in circumstances of famine.

If, as we believe, a woman's own fetal growth and diet and body composition before and during pregnancy play a major role in programming the future health of the children, mothers will want to know what they can do to optimize the intrauterine environment they provide for their babies. The complexities of fetal growth and development are, however, such that currently available data from no basis for changing dietary recommendations for pregnant women. The long time-scale over which the effects of an adverse intrauterine environment act dictate that we now need to progress beyond epidemiologic associations to greater understanding of the cellular and molecular processes that underlie them.

\section{REFERENCES}

1. Avery's Diseases of Newborn; Taeusch, Ballard and Gleasn; 2005 (Saunders)

2. Vingt LAM. Lodeiro JG, Feins SJ. Value of Fetal ponderal index in predicting growth retardation. Obseter Gysetet Gynecol 1986; 67; 584-8.

3. Chellani HK, Mahajan J, Batra A. Fetal poderal index in predicting growth retardation Indian J Med Res 1990; 92; 163-6.

4. Stoikov S, Popov I. The intrauterine Ponderal Index as a prognostic factor in fetal Retardation. Akush Ginekol (Sofia) 1994; 33:3-5.

5. Dombrowski MP, Berry SM.Birth weight-length ratios, ponderal indexes, placental weights and birth weight-placental ratios in a large population. Arch Pediatric Adolesc Med 1994; 148; 508-12

6. Blick-Stein 1, Manor M. The intrauterine ponderal index in relation to birth weight discordance in twin gestations, Int $\mathrm{J}$ Gynaecol Obstet 1995; 50:253-5.

7. Tamin H, Beydoun H, Intani M. Predicting neonatal outcomes; birth weight, body mass index or ponderal index? .J. Perinat Med 2004; 32:509-13.

8. Fay RA, Dey PL. Ponderal index; a better definition of the "At risk" group with intrauterine growth problems than birth -weight for gestational age in term infants, Aust N Z J Obstet Gynaecol 1991; 31:17-19

9. Lin C, Su S, River L; Comparison of associated high risk factors and perinatal outcome between symmetric and asymmetric fetal IUGR. Am J Obstet Gynaecol 1995; 85:558-564.

10. Villar J, de Onism Kestler E et al : The different neonatal morbidity of IUGR; Am J Obsetet Gynaecol 1990; 163: 151-157. 
11. Kramer M, Oliver M, McLean F et al; Impact of intrauterine growth retardation and body proportionality on fetal and neonatal outcome, Pdiatrics 1990; 86; 707-713.

12. Spinillo A, Cappuzo E, Piazzi E et al: Maternal high risk factors and severity of growth deficit in small for gestational age infants: Early hum development 1994; 38:35-43.

13. Alexander GR, Kogan MD, Himes JH et al: Racial differences in birth weight gestational age and infant mortality in extremely low risk population. Paediatr perinat epidemiol 1999; 13:205-217.

14. Seeds J, Peng T: Impaired growth and risk of fetal death: is the tenth percentile appropriate standard? Am J Obstet Gynaecol 178: 658-669, 1998.

15. Kramer, M.S. \& Vectora, C.G. (2001) Low birth weight and perinatal mortality. In: Nurtition and Health in Developing Countries (Semba, R.D. \& Bloem, M.W., eds.) pp. 57-69. Humana Press, Totowa, NJ.

16. Allain C, Poon L, Richmond N. Enzymatic determination of total cholesterol Clin. Chem 20/4 (1974): 470-475.

17. Werner M, Gabrielson DG, Eastman G. Ultra micro determination of serum TG by bioluminescent assay. Clin Chem $1981 ; 27 ; 268-71$.

18. Burnstein M.M, Miller G.J. Gidez L.I. Phosphotungstate Mg2 = precipitation method for $\mathrm{HDL}$-cholesterol quantitation. jr. lipidres 1970; 11; 583.
19. Harold Varley: practical clinical biochemistry 4th edition CBS publication.

20. Lackman F: risk of spontaneous preterm delivery and perinatal mortality in relation to size at birth: Am J Obstet Gynaecol 2001; 184: 946-953.

21. Lucas A. Programming by early nutrition in man. In: Bock GR, Whelan J, eds. The childhood environment and adult disease. Chichester, United Kingdom: John Weley and Sons, 1991: 38-55.

\section{Source of Support: Nil. Conflict of Interest: None Declared.}

Copyright: (c) the author(s) and publisher. IJMRP is an official publication of Ibn Sina Academy of Medieval Medicine \& Sciences, registered in 2001 under Indian Trusts Act, 1882.

This is an open access article distributed under the terms of the Creative Commons Attribution Non-commercial License, which permits unrestricted non-commercial use, distribution, and reproduction in any medium, provided the original work is properly cited.

Cite this article as: Shadab Khalid, Khalid Beg, Ranjit Ambad. Study of Lipid Profile in Cases of Intrauterine Growth Retardation. Int J Med Res Prof. 2016; 2(5):97-102. 